\title{
Similar cerebral protective effectiveness of antegrade and retrograde cerebral perfusion combined with deep hypothermia circulatory arrest in aortic arch surgery: A meta-analysis and systematic review of 5060 patients
}

\author{
Zhipeng $\mathrm{Hu}$, PhD, Zhiwei Wang, MD, Zongli Ren, MD, Hongbing Wu, PhD, Min Zhang, MD, \\ Hao Zhang, $\mathrm{PhD}$, and Xiaoping $\mathrm{Hu}, \mathrm{MD}$
}

\begin{abstract}
Objective: Our objective was to determine if antegrade cerebral perfusion (ACP) and retrograde cerebral perfusion (RCP) combined with deep hypothermia circulatory arrest in aortic arch surgery results in different mortality and neurologic outcomes.
\end{abstract}

\begin{abstract}
Methods: The Cochrane Library, Medline, EMBASE, CINAHL, Web of Science, and the Chinese Biomedical Database were searched for studies reporting on postoperative strokes, permanent neurologic dysfunction, temporary neurologic dysfunction, and all causes mortality within 30 days postoperation in aortic arch surgery. Meta-analysis for effect size, $t$ test, and $I^{2}$ for detecting heterogeneity and sensitivity analysis for assessing the relative influence of each study was performed.
\end{abstract}

Results: Fifteen included studies encompassed a total of 5060 patients of whom 2855 were treated with deep hypothermic circulatory arrest plus ACP and 1897 were treated with deep hypothermic circulatory arrest plus RCP. Pooled analysis showed no significant statistical difference $(P>.01)$ of 30-day mortality, permanent neurologic dysfunction, and transient neurologic dysfunction in the 2 groups. Before sensitivity analysis, postoperative stroke incidence in the ACP group was higher than in the RCP group $(7.2 \%$ vs $4.7 \% ; P<.01)$. After a study that included a different percentage of patients with a history of central neurologic events in the 2 groups was ruled out, postoperative stroke incidence in the 2 groups also showed no significant statistical difference $(P>.01)$.

Conclusions: ACP and RCP provide similar cerebral protective effectiveness combined with deep hypothermia circulatory arrest and could be selected according to the actual condition in aortic arch surgery. A high-quality randomized controlled trial is urgently needed to confirm this conclusion, especially for stroke morbidity following ACP or RCP. (J Thorac Cardiovasc Surg 2014;148:544-60)

\section{Earn CME credits at}

http://jtcvs.com/cme/home

Despite the progress made in the past decades in aortic arch surgery, this kind of procedure is associated with a high rate of mortality and morbidity. ${ }^{1}$ This is not due to the technical difficulties of the procedure, but mainly to the necessity of protecting the integrity of the central nervous system during the period of arch exclusion. ${ }^{2}$

From the Department of Cardiothoracic Surgery, Renmin Hospital of Wuhan University, Hubei Province, Wuhan, China.

Supported by natural science funds of Hubei Province (No. 2008CHB421).

Disclosures: Authors have nothing to disclose with regard to commercial support.

Received for publication May 2, 2013; revisions received Sept 18, 2013; accepted for publication Oct 11, 2013; available ahead of print Dec 11, 2013

Address for reprints: Zhiwei Wang, MD, Department of Cardiothoracic Surgery, Renmin Hospital of Wuhan University, 99 Ziyang Rd, Wuhan, Hubei Province 430060, People's Republic of China (E-mail: wangzhiwp@gmail.com).

0022-5223/\$36.00

Copyright $($ C 2014 by The American Association for Thoracic Surgery

http://dx.doi.org/10.1016/j.jtcvs.2013.10.036
Deep hypothermic circulatory arrest (DHCA) has been used in aortic arch surgery as an effective cerebral protective technique for more than 3 decades and has been refined by Griepp and colleagues. ${ }^{3,4}$ Although hypothermia has proven to be a feasible means of protection of any organ, a time-dependent cascade of events resulting in brain cell injury is initiated. Concerns about the increased mortality and risk of neurologic deficit led to implementation of adjuncts, such as antegrade cerebral perfusion (ACP) and retrograde cerebral perfusion (RCP), which might enhance the safety of the DHCA technique. ${ }^{5}$

Both ACP and RCP have their own advantages and disadvantages. ACP can provide independent control of temperature and/or flow to the cerebral and systemic circulation, but has the potential for embolization. RCP can flush potential embolus from the cerebral circulation and it avoids manipulation of the arch vessel, but the cerebral perfusion capability of RCP is unclear. ${ }^{6,7}$ Furthermore, venous valves may compromise blood flow and RCP may result in cerebral edema. ${ }^{8}$

Unfortunately, a high-quality, multicentric, randomized controlled trial comparing the effectiveness of ACP and 


\section{Abbreviations and Acronyms \\ $\mathrm{ACP}=$ antegrade cerebral perfusion \\ DHCA $=$ deep hypothermic circulatory arrest \\ PND = permanent neurologic dysfunction \\ $\mathrm{RCP}=$ retrograde cerebral perfusion \\ $\mathrm{TND}=$ transient neurologic dysfunction}

RCP combined with DHCA in preventing neurologic deficit is absent, making it difficult to draw any meaningful conclusions as to which treatment option is better. The aim of our study was to assess the risk of neurologic complications by meta-analysis of published trials comparing ACP and RCP combined with DHCA.

\section{METHODS}

We searched the Cochrane Central Register of Controlled Trials in the Cochrane Library, Medline, EMBASE, CINAHL, Web of Science, and the Chinese Biomedicine Database for studies until April 26, 2013. The following free text search string was used: "human and antegrade cerebral perfusion or retrograde cerebral perfusion or selective cerebral perfusion or antegrade brain perfusion or ACP or ASCP or RCP or cerebral protection or hypothermia circulatory arrest or HCA or DHCA and comparative study or randomized controlled trial."

Studies that evaluated the cerebral protective effectiveness of ACP and RCP combined with DHCA were included. We looked for studies that gave at least 1 of the following clinical outcomes: all-cause mortality within 30 days, morbidity of transient neurologic dysfunction (TND) (defined as postoperative confusion, agitation, delirium, prolonged obtundation, or transient parkinsonism), permanent neurologic dysfunction (PND) (ie, presence of permanent neurologic deficits that were focal or global in nature and persisting at discharge from the hospital), and stroke (defined as a serious illness caused when a blood vessel in the brain suddenly breaks or is blocked, diagnosed by computed tomography or magnetic resonance imaging). ${ }^{9}$

Two authors (Drs Zhipeng and Hongbing) independently identified trials for inclusion and extracted information on demographics, interventions, and outcomes. Disagreements were resolved by consensus. For dichotomous and continuous variables, risk ratios (RRs), $95 \%$ confidence intervals (CIs), and odds ratios (ORs) were calculated. And for continuous variables, mean difference and $95 \%$ CIs were calculated. Statistical heterogeneity was measured using the $Q$ statistic and $I^{2}$ test $\left(Q<0.10\right.$ or $I^{2}>50 \%$ was considered an indication of statistically significant heterogeneity). For each outcome, the fixed effect model (Mantel-Haenszel test for dichotomous variables and inverse variance for continuous variables) or random effects model (DerSimonian and Laird method for dichotomous and continuous variables) was used when the $Q$ statistic suggested lack or presence of heterogeneity, respectively. The sensitivity analyses were used to assess the relative influence of each study on pooled estimates by omitting 1 study at a time. Finally, we assessed the publication bias by using funnel plots. All analyses were done with Stata software (version 12, StataCorp LP, College Station, Tex).

\section{RESULTS}

\section{Included Studies}

Of 1843 potentially relevant studies, 15 comparative studies met the selection criteria and were included ${ }^{10-24}$ (Figure 1). No randomized controlled trial is available. The included studies encompassed a total of 5060 patients

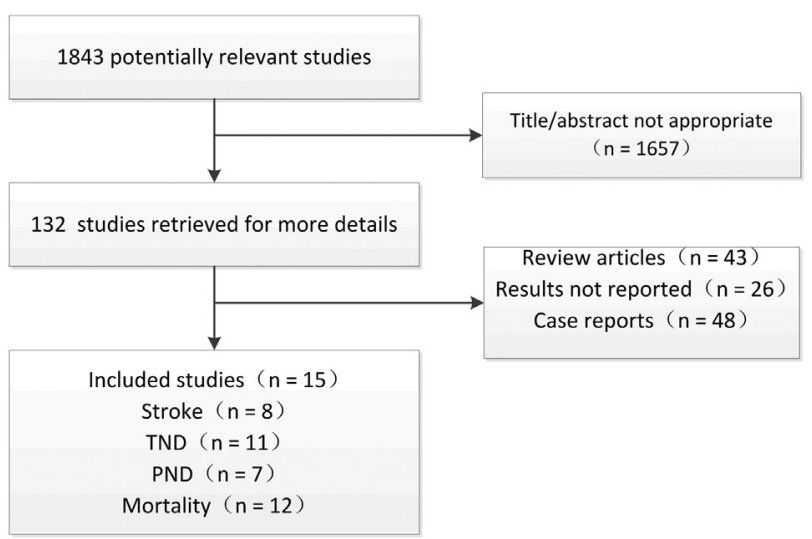

FIGURE 1. Flow diagram of study selection. $T N D$, Transient neurologic dysfunction; $P N D$, permanent neurologic dysfunction.

of whom 3156 were treated with DHCA + ACP and 1904 were treated with DHCA + RCP. Baseline patient characteristics and main intraoperative details are shown in Table 1. A significant difference only exists in the comparison of the central neurologic event's history before surgery between the 2 groups $(P<.01)$. Unfortunately, some important information about proportions of acute and/or chronic dissections, of redo procedures, the extent of the aortic replacement, and the type of cannulation were only presented by part of the studies and could not be compared. Quality assessment of each comparison was done by the GRADE system and the quality of each comparison is only from very low to low (Table 2). ${ }^{25-27}$ That may be due to the low quality of the original studies (Figure 2).

\section{Neurologic Complications}

Stroke. Postoperative strokes were observed in 8 trials comprising a total of 222 events among 3429 patients. Meta-analysis of these studies using a fixed-effects model $\left(P=.40 ; I^{2}=3.9 \%\right)$ revealed that ACP accounts for higher morbidity of stroke. (Mantel-Haenszel fixed RR, 1.86; 95\% CI, 1.30-2.65; $P=.001$ ) (Figure 3). A funnel plot showed significant publication bias existed (Figure 4).

TND. Postoperative TND was observed in 11 trials comprising a total of 316 events among 4417 patients. The incidence of postoperative TND was $7.50 \%$ in the ACP group and $8.7 \%$ in the RCP group. No significant difference existed (Mantel-Haenszel fixed RR, $0.89 ; 95 \% \mathrm{CI}$, $0.72-1.1 ; P=.275)$. There was no heterogeneity between the 2 groups $\left(P=.154 ; I^{2}=29.8 \%\right)$ (Figure 5). The funnel plot showed no evidence of publication bias (Figure 6).

PND. Postoperative PND was reported in 2904 ACP patients and 1583 RCP patients from 7 studies. There was no evidence of heterogeneity $\left(P=.525 ; I^{2}=0 \%\right)$. Difference in postoperative PND incidence was not significant between the 2 groups ( $6 \%$ vs $4.7 \%$, Mantel-Haenszel fixed RR, 1.02; 95\% CI, 0.75-1.37; $P=.911$ ) (Figure 7). The funnel plot showed no evidence of publication bias (Figure 8). 
TABLE 1. Baseline data for this study

\begin{tabular}{|c|c|c|c|c|c|c|c|c|c|c|c|c|c|c|c|}
\hline \multirow[b]{2}{*}{ Study } & \multirow[b]{2}{*}{ Methods } & \multirow[b]{2}{*}{$\mathbf{n}$} & \multirow[b]{2}{*}{ Age, $y$} & \multirow[b]{2}{*}{ Men } & \multirow[b]{2}{*}{ HCNE } & \multirow[b]{2}{*}{ PCS } & \multirow[b]{2}{*}{ Dissec-tion } & \multirow[b]{2}{*}{ Aneurysm } & \multirow[b]{2}{*}{ DHCA time } & \multirow[b]{2}{*}{ CPB time } & \multirow[b]{2}{*}{$\begin{array}{c}\text { Core } \\
\text { temperature }\end{array}$} & \multirow[b]{2}{*}{$\begin{array}{l}\text { Circulatory } \\
\text { arrest time }\end{array}$} & \multirow[b]{2}{*}{ CP time } & \multicolumn{2}{|c|}{ Arch replacement type } \\
\hline & & & & & & & & & & & & & & Hemi & Total \\
\hline \multirow{2}{*}{ Okita 2001} & $\mathrm{ACP}$ & 30 & $67.6 \pm 8.5$ & 25 & 0 & NA & 27 & 3 & $54.5 \pm 26.2$ & $215 \pm 83$ & $22.1 \pm 3.0$ & NA & $117 \pm 40.3$ & NA & NA \\
\hline & $\mathrm{RCP}$ & 30 & $69.1 \pm 10$ & 24 & 2 & NA & 25 & 5 & $44.3 \pm 13.9$ & $175 \pm 58$ & $17.6 \pm 2.4$ & $44.3 \pm 13.9$ & $33.1 \pm 11.4$ & NA & NA \\
\hline \multirow[t]{2}{*}{ Matalanis 2003} & $\mathrm{ACP}$ & 25 & $66.5 \pm 12.85$ & 21 & 6 & 6 & 4 & 1 & $11.4 \pm 9.6$ & $247.8 \pm 86.4$ & $\sim 19$ & $61.8 \pm 44.1$ & $49.6 \pm 0.5$ & 19 & 6 \\
\hline & $\mathrm{RCP}$ & 23 & $62.7 \pm 11.1$ & 16 & 2 & 4 & 9 & 17 & $37.4 \pm 19.2$ & $193.5 \pm 34.9$ & $\sim 19$ & $36.4 \pm 20.5$ & $30.6 \pm 19.0$ & 17 & 6 \\
\hline \multirow[t]{2}{*}{ Neri 2004} & $\mathrm{ACP}$ & 25 & $59.9 \pm 7.6$ & 17 & NA & NA & 7 & 5 & NA & $164 \pm 32.2$ & $20.9 \pm 1.7$ & NA & NA & 15 & 10 \\
\hline & $\mathrm{RCP}$ & 19 & $69.9 \pm 3.8$ & 14 & NA & NA & 18 & 14 & NA & $172.4 \pm 47.9$ & $20.9 \pm 1.1$ & NA & NA & 10 & 9 \\
\hline \multirow[t]{2}{*}{ Zierer 2005} & $\mathrm{ACP}$ & 38 & $62 \pm 11$ & 28 & 3 & 2 & NA & 1 & NA & $120 \pm 50$ & $21 \pm 1.3$ & NA & $23 \pm 9$ & NA & NA \\
\hline & $\mathrm{RCP}$ & 18 & $55 \pm 11$ & 9 & 1 & 0 & NA & 1 & NA & $176 \pm 34$ & $20.8 \pm 2.4$ & NA & $29 \pm 13$ & NA & NA \\
\hline \multirow[t]{2}{*}{ Han 2007} & ACP & 35 & NA & NA & NA & NA & 14 & 21 & $51.3 \pm 19$ & $181.1 \pm 73$ & $16 \pm 22$ & NA & NA & 24 & 6 \\
\hline & $\mathrm{RCP}$ & 43 & NA & NA & NA & NA & 19 & 24 & $46.6 \pm 17.1$ & $168.7 \pm 59.5$ & $16 \pm 22$ & NA & NA & 29 & 8 \\
\hline \multirow{4}{*}{$\begin{array}{l}\text { Apostolakis } \\
2008 \\
\text { Sundt } 2008\end{array}$} & $\mathrm{ACP}$ & 23 & $61 \pm 15.6$ & 16 & 2 & NA & 33 & NA & $39 \pm 13.16$ & $179 \pm 28.65$ & $16 \pm 20$ & $39 \pm 13.16$ & $37 \pm 14$ & 13 & 10 \\
\hline & $\mathrm{RCP}$ & 25 & $60 \pm 17.1$ & 20 & 1 & NA & 25 & NA & $36 \pm 12.73$ & $184 \pm 33.12$ & $16 \pm 20$ & $36 \pm 12.73$ & $34 \pm 12$ & 17 & 5 \\
\hline & $\mathrm{ACP}$ & 74 & $64 \pm 16$ & 36 & 8 & 26 & 25 & 39 & $41 \pm 28$ & $188 \pm 62$ & NT $16-18$ & $41 \pm 28$ & NA & 24 & 82 \\
\hline & $\mathrm{RCP}$ & 53 & $71 \pm 8$ & 27 & 2 & 12 & 18 & 28 & $33 \pm 13$ & $176 \pm 65$ & NT $16-18$ & $33 \pm 13$ & NA & 32 & 26 \\
\hline \multirow[t]{2}{*}{ Apaydin 2009} & $\mathrm{ACP}$ & 19 & $60 \pm 13$ & NA & NA & NA & NA & NA & $28 \pm 12$ & $251 \pm 66$ & $\sim 16$ & $28 \pm 12$ & $73 \pm 26$ & NA & NA \\
\hline & $\mathrm{RCP}$ & 94 & $54 \pm 12$ & NA & NA & NA & NA & 4 & $40 \pm 11$ & $183 \pm 41$ & $\sim 16$ & $40 \pm 11$ & $40 \pm 11$ & NA & NA \\
\hline \multirow[t]{2}{*}{ Forteza 2009} & $\mathrm{ACP}$ & 26 & NA & NA & NA & NA & NA & 4 & $\mathrm{NA}$ & NA & $\sim 18$ & NA & NA & NA & NA \\
\hline & $\mathrm{RCP}$ & 23 & NA & NA & NA & NA & NA & NA & NA & NA & $\sim 18$ & NA & NA & NA & NA \\
\hline \multirow[t]{2}{*}{ Milewski 2010} & $\mathrm{ACP}$ & 94 & $64.1 \pm 11.5$ & 60 & 13 & 20 & 5 & 89 & $34.5 \pm 8.1$ & $171.2 \pm 50.3$ & NA & $34.5 \pm 8.1$ & $30.7 \pm 7.5$ & NA & NA \\
\hline & $\mathrm{RCP}$ & 682 & $59.9 \pm 15.3$ & 467 & 80 & 168 & 68 & 637 & $25.0 \pm 9.7$ & $222.9 \pm 63.7$ & NA & $25 \pm 9.7$ & $25 \pm 9.7$ & NA & NA \\
\hline \multirow[t]{2}{*}{ Sugiura 2012} & $\mathrm{ACP}$ & 94 & $67.2 \pm 9.3$ & 45 & NA & NA & NA & NA & $65 \pm 15$ & $229 \pm 72$ & $25.6 \pm 1.2$ & NA & NA & NA & NA \\
\hline & $\mathrm{RCP}$ & 109 & $65.6 \pm 11.7$ & 53 & NA & NA & NA & NA & $53 \pm 16$ & $211 \pm 51$ & $23.7 \pm 1.1$ & NA & NA & NA & NA \\
\hline Wiedemann & $\mathrm{ACP}$ & 91 & $62(33-85)$ & 63 & 3 & 5 & NA & NA & $47(18-150)$ & $161(101-303)$ & ET 18 & $30(14-92)$ & NA & NA & 4 \\
\hline 2012 & $\mathrm{RCP}$ & 122 & $56(18-87)$ & 75 & 9 & 7 & NA & NA & $63(30-162)$ & $198(121-404)$ & ET 18 & $30(14-88)$ & NA & NA & 3 \\
\hline Usui 2012 & $\mathrm{ACP}$ & 2209 & $70.4 \pm 9.9$ & 642 & 342 & 146 & NA & NA & NA & NA & NA & NA & NA & NA & NA \\
\hline & $\mathrm{RCP}$ & 583 & $66.9 \pm 11.4$ & 393 & 64 & 49 & NA & NA & NA & NA & NA & NA & NA & NA & NA \\
\hline Misfeld 2012 & $\mathrm{ACP}$ & 365 & $63 \pm 13$ & 234 & 23 & 51 & 149 & 27 & $23.7 \pm 19.7$ & $210 \pm 76$ & $22 \pm 2$ & $18 \pm 12$ & NA & 42 & 238 \\
\hline & $\mathrm{RCP}$ & 51 & $62 \pm 14$ & 38 & 5 & 12 & 14 & 216 & $18 \pm 12$ & $205 \pm 60$ & $22 \pm 2$ & $23 \pm 20$ & NA & 9 & 137 \\
\hline Williams 2012 & $\mathrm{ACP}$ & 8 & $61.5 \pm 11.7$ & 5 & 2 & 0 & NA & NA & $34 \pm 11$ & $190 \pm 43$ & $17 \pm 4.1$ & NA & NA & 7 & 1 \\
\hline & $\mathrm{RCP}$ & 29 & $59.2 \pm 13.7$ & 20 & 0 & 2 & NA & NA & $33 \pm 11$ & $188 \pm 58$ & $19 \pm 2.7$ & NA & NA & 28 & 1 \\
\hline $\begin{array}{l}P \text { for ACP vs } \\
\text { RCP }\end{array}$ & & & .68 & .17 & $<.01$ & 0.18 & $\mathrm{NC}$ & $\mathrm{NC}$ & .56 & .47 & $\mathrm{NC}$ & $\mathrm{NC}$ & $\mathrm{NC}$ & $\mathrm{NC}$ & $\mathrm{NC}$ \\
\hline
\end{tabular}

Data are presented as number, median (range), or number (\%). Times are given in minutes and temperatures are given in ${ }^{\circ} \mathrm{C} . H C N E$, History of central neurologic events; $P C S$, previous cardiovascular surgery; $D H C A$, deep
hypothermic circulatory arrest; $C P B$, cardiopulmonary bypass; $C P$, cerebral perfusion; $A C P$, antegrade cerebral perfusion; $N A$, not applicable; $R C P$, retrograde cerebral perfusion; $N T$, nasopharynx temperature; $E T$, esophageal temperature; $N C$, not comparable because too much data not available. 
TABLE 2. Quality assessment of each comparison, describing in detail the principal findings of this review and the quality of the evidence for each outcome using the GRADE approach ${ }^{25-27}$

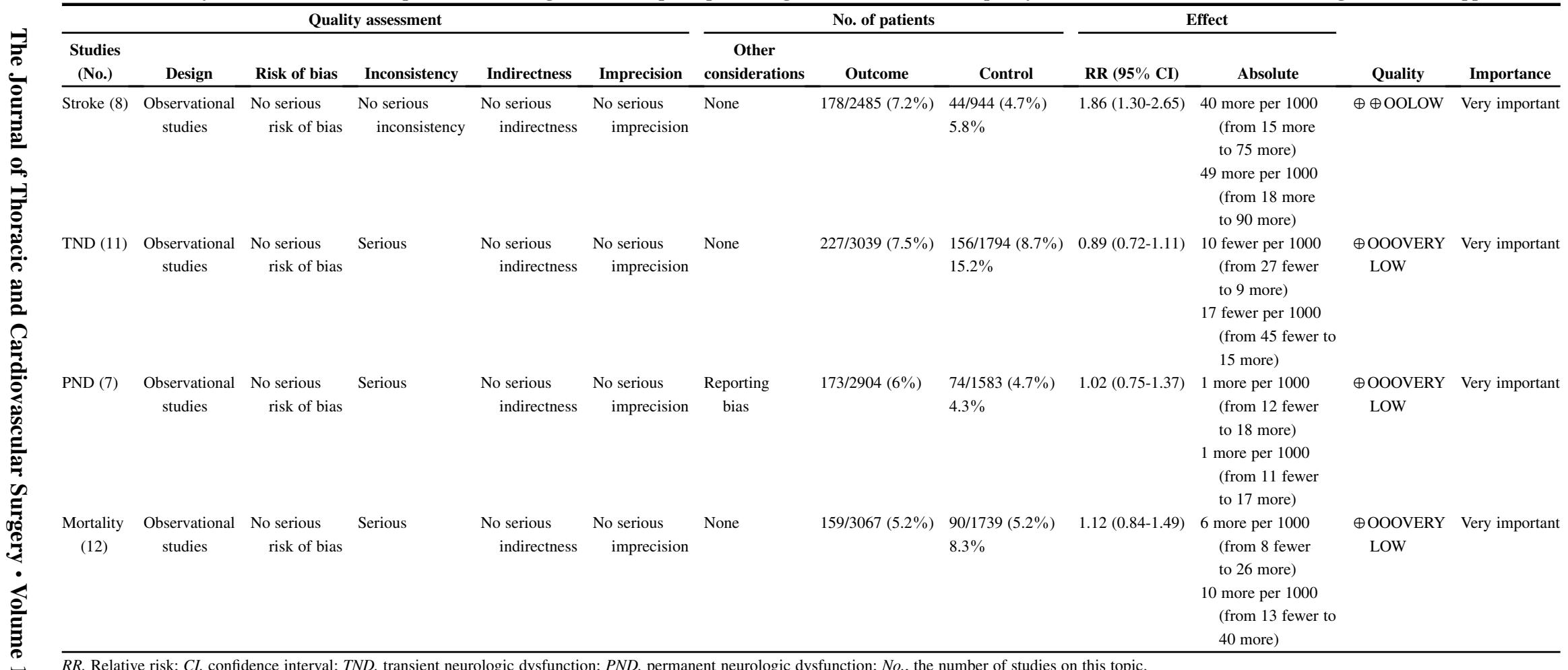

空

㹂 


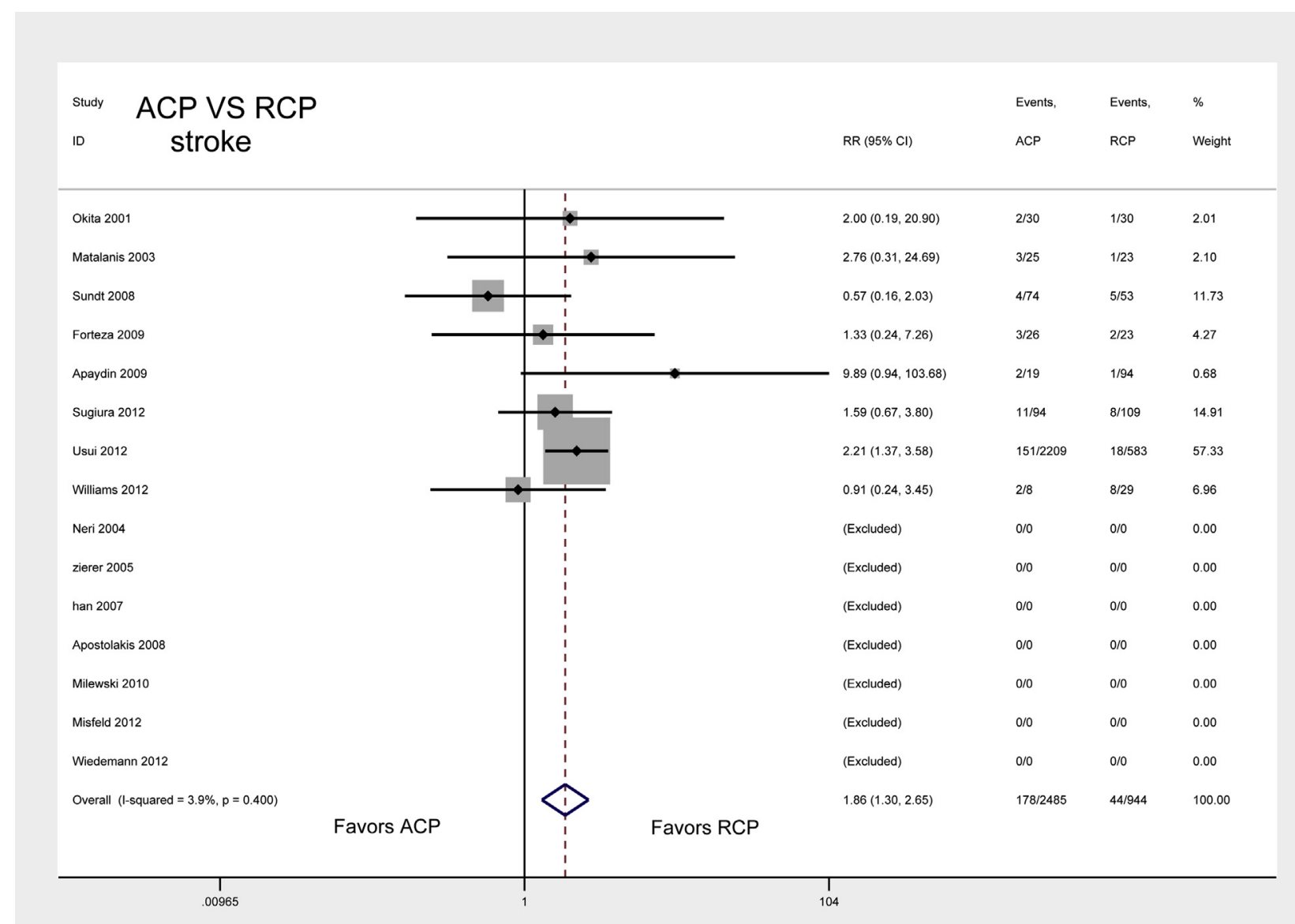

FIGURE 2. Quality assessment of each original study. $A C P$, Antegrade cerebral perfusion; $R C P$, retrograde cerebral perfusion; $R R$, relative risk; $C I$, confidence interval.

\section{Mortality}

All-cause deaths within 30 days were observed in 12 studies comprising a total of 249 events among 4806 patients. The incidence of postoperative mortality was $5.184 \%$ in the ACP group and $5.175 \%$ in the RCP group. No significant difference existed (Mantel-Haenszel fixed RR, 1.12 ; 95\% CI, 0.84-1.49; $P=.432)$; There was no heterogeneity between the 2 groups $\left(P=.175 ; I^{2}=27.5 \%\right)$ (Figure 9). The funnel plots showed significant publication bias existed (Figure 10).

\section{Sensitivity Analysis}

In the sensitivity analysis, the exclusion of any individual studies did not modify estimates of TND, PND, and mortality. But when the study by Usui and colleagues ${ }^{20}$ was excluded, the estimate of stroke morbidity modified significantly (Figures 11 and 12) (RR, 1.86; 95\% CI, 1.30-2.65 vs RR, 1.38; 95\% CI, 0.83-2.32). The significant statistical difference indicated by a $P$ value also disappeared. This indicates that the higher stroke morbidity may come from the patients in the study by Usui and colleagues. ${ }^{20}$
To further rule out the possibility that stroke morbidity is different in ACP and RCP groups, a sensitivity analysis was conducted on the baseline data. When the study by Usui and colleagues $^{20}$ was excluded, the significant statistical difference in central neurologic events history also disappeared, and the estimate of stroke morbidity modified significantly (Figure 13) (RR, 1.33; 95\% CI, 1.08-1.64 vs RR, 1.15; 95\% CI, 0.80-1.66) (Figures 14 and 15). This indicates a higher rate of central neurologic events history before surgery in the patients included in the study by Usui and colleagues. ${ }^{20}$ The higher incidence of stroke may come from including more patients with a history of central neurologic events in the ACP group but not from the ACP procedure.

\section{DISCUSSION}

DHCA was the first method of brain protection successfully used in aortic arch surgery but has temporal limits. Both ACP and RCP have additional brain protective effects, but along with those are potential risks. Theoretically, ACP may present higher risk of cerebral embolism, whereas RCP 


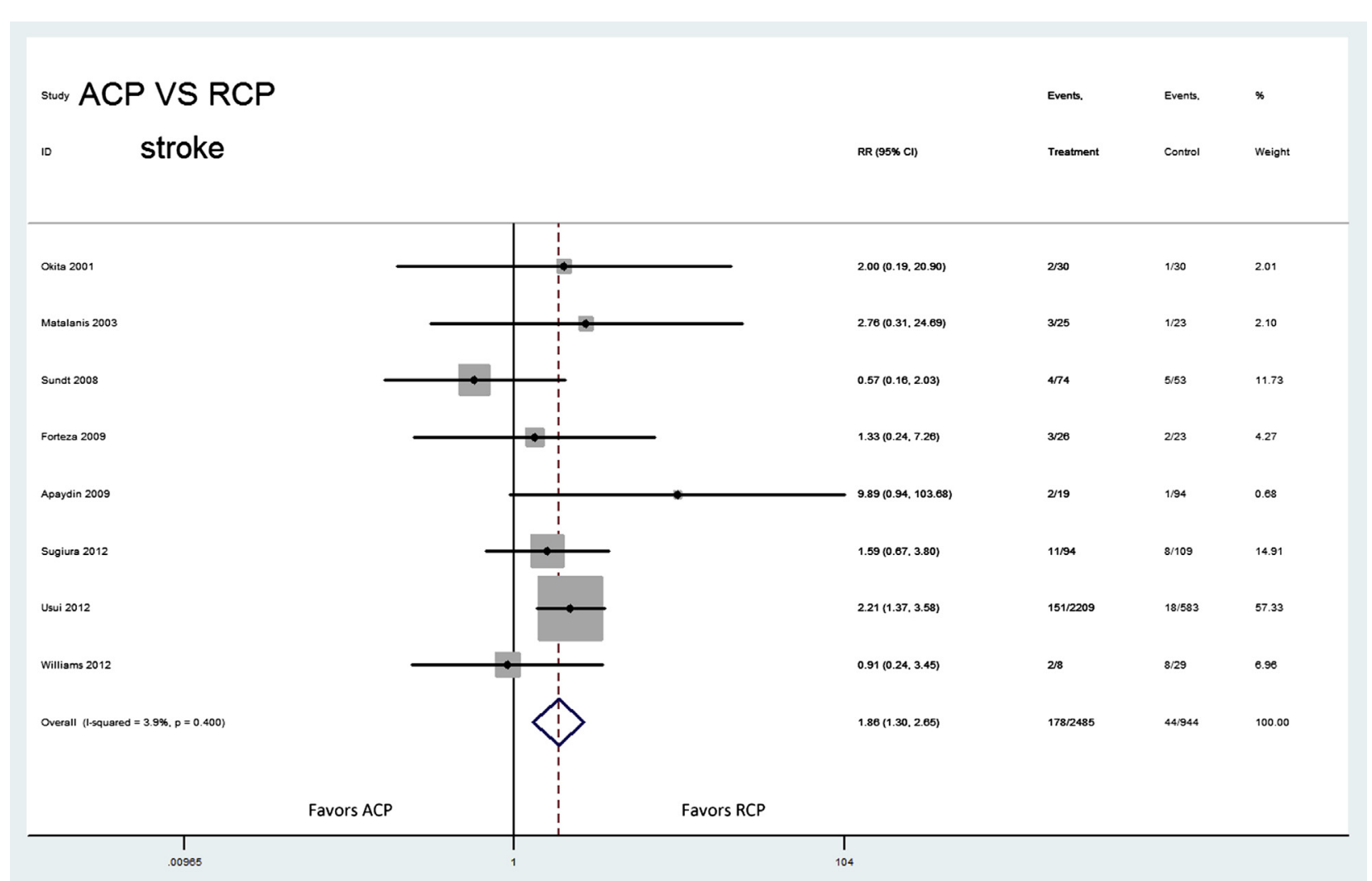

FIGURE 3. Comparison of antegrade cerebral perfusion $(A C P)$ versus retrograde cerebral perfusion $(R C P)$ for morbidity of postoperative stroke. $R R$, Relative risk; $C I$, confidence interval.

may present higher risk of cerebral hypoperfusion. ${ }^{8}$ No consensus has been reached on which procedure-ACP or RCP_-gives better clinical brain protection effectiveness. The main finding of our study is that no difference exists between ACP and RCP in regard to protecting the central cerebral system during aortic arch surgery.

Although Usui and colleagues ${ }^{20}$ drew a conclusion by risk-adjusted analysis that both RCP and ACP provide comparable clinical outcomes regarding stroke rates, when their data was entered into our meta-analysis, both central neurologic events history before surgery as baseline data and stroke incidence as a result are significantly different between the ACP and RCP groups. Fortunately, we successfully ruled out such a special patient group with a discrepant baseline with the help of the strong sensitivity analysis function of Stata software and drew an absolute opposite conclusion, which means, based on similar baseline data, that ACP and RCP account for the same postoperative stroke rates. Previous investigators also identified history of central neurologic events as a predictor of postoperative stroke. $^{28,29}$ Those studies provide further support to our finding.

When compared with other clinical neurologic outcomes, such as TND, PND, and all-cause deaths within 30 days, ACP and RCP provide similar protection effectiveness.
Several studies have reported that PND is more likely to occur after ACP because of embolism and TND was more likely to occur after RCP because of global ischemia and a longer cerebral ischemic time. ${ }^{29-32}$ In our meta-analysis, there was no difference in TND and PND between the RCP group and the ACP group, suggesting that both techniques provide acceptable cerebral outcomes. The technique best suited to the individual patient can therefore be selected.

This meta-analysis focused on the influence of cerebral protective method selected on the main neurologic complications that result. Other clinical results such as respiratory failure, renal failure, hepatic injury, and cardiovascular accident were not compared. This is partially because of the dominant incidence of neurologic complications after arch surgery and their bad prognosis. So our conclusion is most valuable when used as a resource to select a better cerebral scheme when the prevention of neurologic complications is most important.

Because ACP and RCP worked equally well with DHCA, it seems that hypothermia was the key ingredient and the perfusion was nonessential. In fact, our meta-analysis could have been designed to compare DHCA alone, DHCA + ACP, or DHCA + RCP. But only a few studies compared results from these 3 methods and there are not 


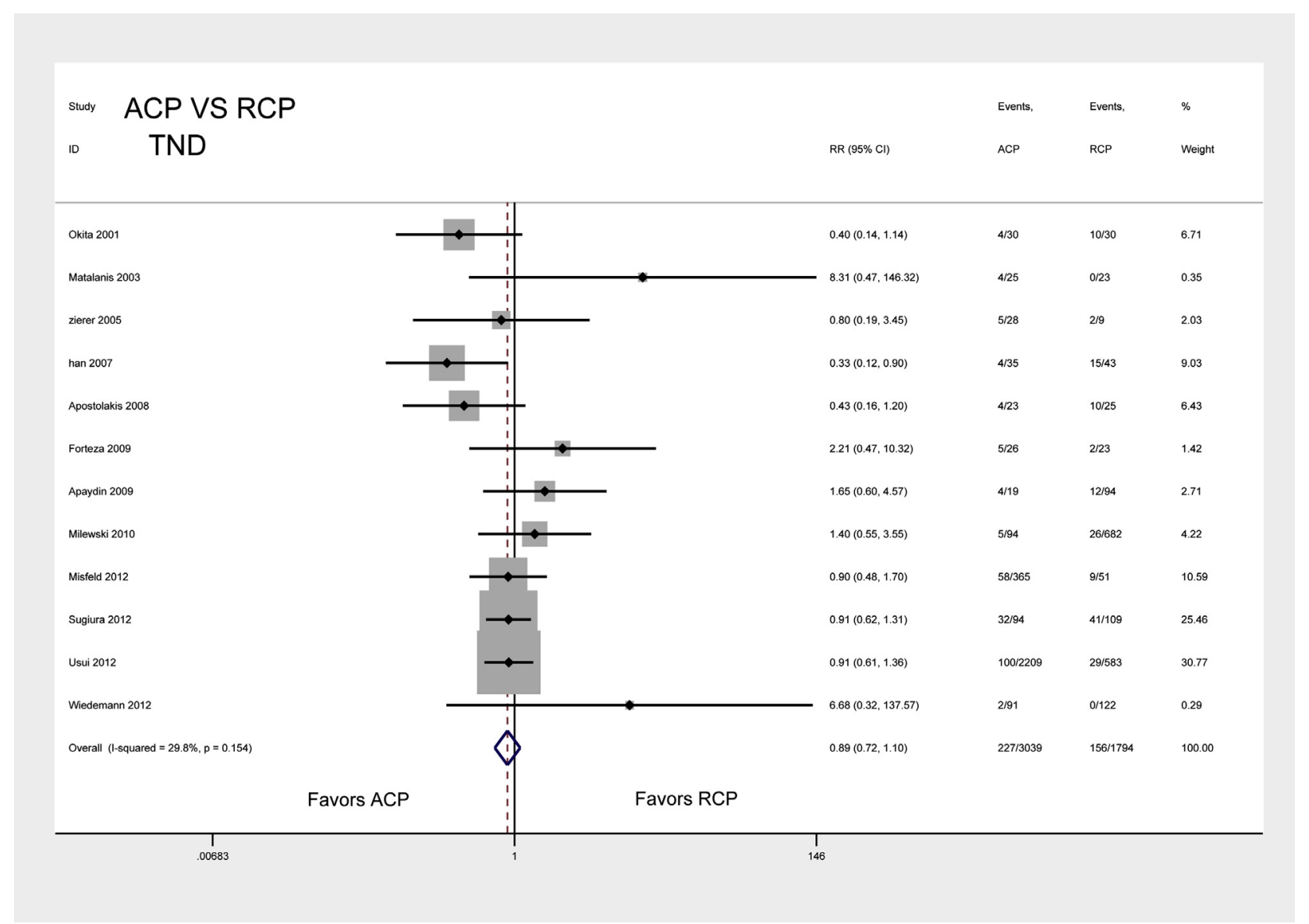

FIGURE 4. Funnel plot of comparison: Morbidity of postoperative stroke. $A C P$, Antegrade cerebral perfusion; $R C P$, retrograde cerebral perfusion; $T N D$, transient neurologic dysfunction; $R R$, relative risk; $C I$, confidence interval.

enough data for a meta-analysis. But most of these studies reached the same conclusion that DHCA + ACP or RCP are better than DHCA alone, especially when the requiring brain protection time is longer than 30 minutes. ${ }^{10,14,16,29,33}$

We assessed the quality of the original studies by the GRADE system. Although the quality of each study is not so high and the level of evidence provided by the studies is weak, the conclusion of this meta-analysis is still valuable-especially before a high-quality RCT is published.

There are limitations to this meta-analysis. First, no randomized controlled trial is available and the quality of each study included is low, so a high-quality meta-analysis of randomized controlled trials could not be performed. Second, some of the important baseline data are not available, such as hypertension and peripheral vascular disease. This prevented us from comparing clinical outcomes of ACP and RCP based on more similar baseline data.

\section{CONCLUSIONS}

ACP and RCP provide similar cerebral protective effectiveness when combined with DHCA and could be selected according to the actual condition in aortic arch surgery. A high-quality randomized controlled trial is urgently needed to confirm this conclusion, especially for stroke morbidity following ACP or RCP.

\section{References}

1. Bachet J. What is the best method for brain protection in surgery of the aortic arch? Selective antegrade cerebral perfusion. Cardiol Clin. 2010;28: 389-401.

2. Yekeler I, Ates A, Ozyazicioglu A, Balci AY, Erkut B, Erol MK. Time and risk analysis for acute type A aortic dissection surgery performed by hypothermic circulatory arrest, cerebral perfusion, and open distal aortic anastomosis. Heart Surg Forum. 2005;8:E337-47.

3. Ergin MA, O'Connor J, Guinto R, Griepp RB. Experience with profound hypothermia and circulatory arrest in the treatment of aneurysms of the aortic arch. Aortic arch replacement for acute arch dissections. J Thorac Cardiovasc Surg. 1982;84:649-55.

4. Griepp RB, Stinson EB, Hollingsworth JF, Buehler D. Prosthetic replacement of the aortic arch. J Thorac Cardiovasc Surg. 1975;70:1051-63.

5. Janusz MJ, Tyers FO. Techniques of aortic arch replacement: profound hypothermia versus moderate hypothermia with innominate artery perfusion. Am J Surg. 1987;153:511-3.

6. Ehrlich MP, Hagl C, McCullough JN, Zhang N, Shiang H, Bodian C, et al. Retrograde cerebral perfusion provides negligible flow through brain capillaries in the pig. J Thorac Cardiovasc Surg. 2001;122:331-8.

7. Oohara K, Usui A, Murase M, Tanaka M, Abe T. Regional cerebral tissue blood flow measured by the colored microsphere method during retrograde cerebral perfusion. J Thorac Cardiovasc Surg. 1995;109:772-9.

8. Maas C, Kok R, Segers P, Boogaart A, Ellander S, de Vries I, et al. Intermittent antegrade/selective cerebral perfusion during circulatory arrest for repair of the aortic arch. Perfusion. 1997;12:127-32. 


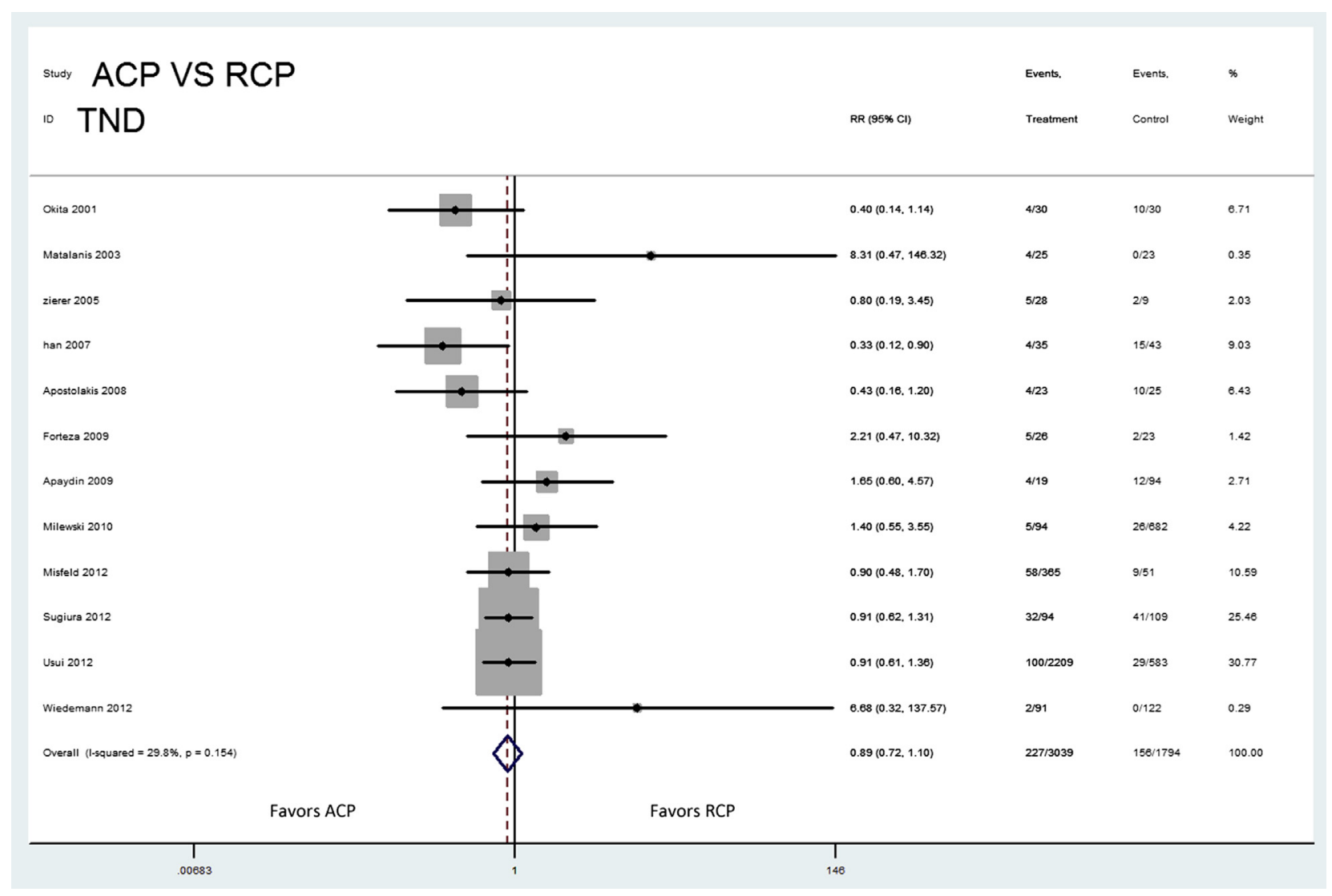

FIGURE 5. Comparison of antegrade cerebral perfusion $(A C P)$ versus retrograde cerebral perfusion $(R C P)$ for morbidity of postoperative transient neurologic dysfunction (TND). RR, Relative risk; $C I$, confidence interval.

9. Ergin MA, Galla JD, Lansman S, Quintana C, Bodian C, Griepp RB. Hypothermic circulatory arrest in operations on the thoracic aorta. Determinants of operative mortality and neurologic outcome. J Thorac Cardiovasc Surg. 1994;107: 788-97.

10. Apaydin AZ, Islamoglu F, Askar FZ, Engin C, Posacioglu H, Yagdi T, et al. Immediate clinical outcome after prolonged periods of brain protection: retrospective comparison of hypothermic circulatory arrest, retrograde, and antegrade perfusion. J Card Surg. 2009;24:486-9.

11. Apostolakis E, Koletsis EN, Dedeilias P, Kokotsakis JN, Sakellaropoulos G, Psevdi A, et al. Antegrade versus retrograde cerebral perfusion in relation to postoperative complications following aortic arch surgery for acute aortic dissection type A. J Card Surg. 2008;23:480-7.

12. Forteza A, Martin C, Centeno J, Lopez MJ, Perez E, de Diego J, et al. Acute type A aortic dissection: 18 years of experience in one center (Hospital 12 de Octubre). Interact Cardiovasc Thorac Surg. 2009;9:426-30.

13. Han QQ, Xu ZY, Zhang BR, Xu JB, Han L, He B, et al. Impact of different brain protection techniques upon postoperative temporary neurological dysfunction in aortic surgery with the aid of deep hypothermic circulatory arrest. Zhonghua Wai Ke Za Zhi. 2007;45:419-22.

14. Matalanis G, Hata M, Buxton BF. A retrospective comparative study of deep hypothermic circulatory arrest, retrograde, and antegrade cerebral perfusion in aortic arch surgery. Ann Thorac Cardiovasc Surg. 2003;9:174-9.

15. Milewski RK, Pacini D, Moser GW, Moeller P, Cowie D, Szeto WY, et al. Retrograde and antegrade cerebral perfusion: results in short elective arch reconstructive times. Ann Thorac Surg. 2010;89:1448-57.

16. Misfeld M, Leontyev S, Borger MA, Gindensperger O, Lehmann S, Legare JF, et al. What is the best strategy for brain protection in patients undergoing aortic arch surgery? A single center experience of 636 patients. Ann Thorac Surg. 2012; 93:1502-8.

17. Neri E, Sassi C, Barabesi L, Massetti M, Pula G, Buklas D, et al. Cerebral autoregulation after hypothermic circulatory arrest in operations on the aortic arch. Ann Thorac Surg. 2004;77:72-9.
18. Sugiura T, Imoto K, Uchida K, Minami T, Yasuda S. Comparative study of brain protection in ascending aorta replacement for acute type A aortic dissection: retrograde cerebral perfusion versus selective antegrade cerebral perfusion Gen Thorac Cardiovasc Surg. 2012;60:645-8.

19. Sundt TR, Orszulak TA, Cook DJ, Schaff HV. Improving results of open arch replacement. Ann Thorac Surg. 2008;86:787-96.

20. Usui A, Miyata H, Ueda Y, Motomura N, Takamoto S. Risk-adjusted and casematched comparative study between antegrade and retrograde cerebral perfusion during aortic arch surgery: based on the Japan Adult Cardiovascular Surgery Database: the Japan Cardiovascular Surgery Database Organization. Gen Thorac Cardiovasc Surg. 2012;60:132-9.

21. Wiedemann D, Kocher A, Dorfmeister M, Vadehra A, Mahr S, Laufer G, et al. Effect of cerebral protection strategy on outcome of patients with Stanford type A aortic dissection. J Thorac Cardiovasc Surg. 2013;146:647-55.

22. Williams ML, Ganzel BL, Slater AD, Slaughter MS, Trivedi JR, Edmonds HL, et al. Antegrade versus retrograde cerebral protection in repair of acute ascending aortic dissection. Am Surg. 2012;78:349-51.

23. Zierer A, Aybek T, Risteski P, Dogan S, Wimmer-Greinecker G, Mortiz A. Moderate hypothermia (30 degrees C) for surgery of acute type A aortic dissection. Thorac Cardiovasc Surg. 2005;53:74-9.

24. Okita Y, Minatoya K, Tagusari O, Ando M, Nagatsuka K, Kitamura S. Prospective comparative study of brain protection in total aortic arch replacement: deep hypothermic circulatory arrest with retrograde cerebral perfusion or selective antegrade cerebral perfusion. Ann Thorac Surg. 2001;72:72-9.

25. Brozek JL, Akl EA, Alonso-Coello P, Lang D, Jaeschke R, Williams JW, et al Grading quality of evidence and strength of recommendations in clinical practice guidelines. Part 1 of 3 . An overview of the GRADE approach and grading quality of evidence about interventions. Allergy. 2009;64:669-77.

26. Brozek JL, Akl EA, Compalati E, Kreis J, Terracciano L, Fiocchi A, et al. Grading quality of evidence and strength of recommendations in clinical practice guidelines part 3 of 3 . The GRADE approach to developing recommendations. Allergy. 2011;66:588-95. 


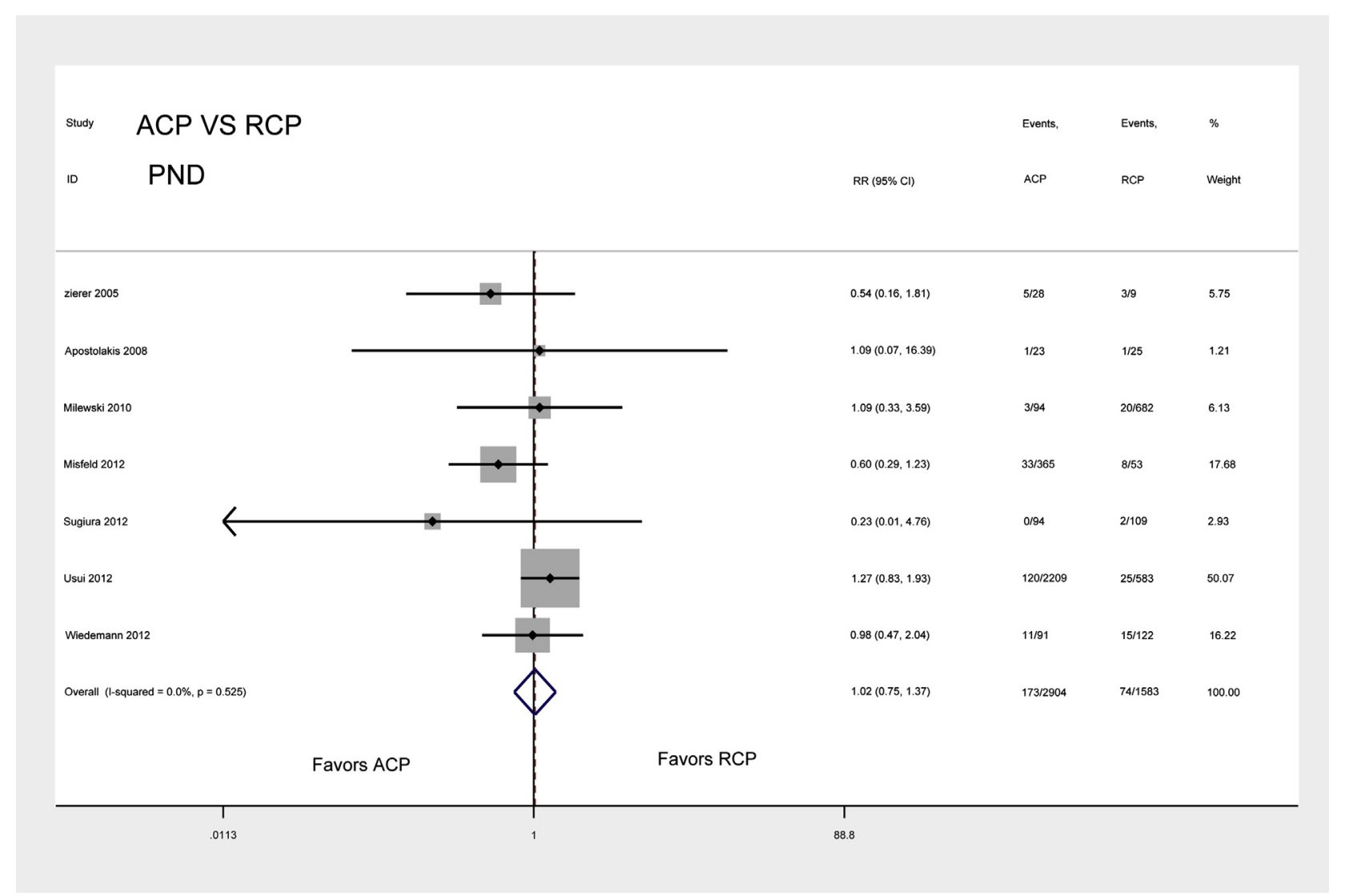

FIGURE 6. Funnel plot of comparison: Morbidity of postoperative transient neurologic dysfunction. ACP, Antegrade cerebral perfusion; $R C P$, retrograde cerebral perfusion; $P N D$, permanent neurologic dysfunction; $R R$, relative risk; $C I$, confidence interval.

27. Brozek JL, Akl EA, Jaeschke R, Lang DM, Bossuyt P, Glsziou P, et al. Grading quality of evidence and strength of recommendations in clinical practice guidelines: part 2 of 3 . The GRADE approach to grading quality of evidence about diagnostic tests and strategies. Allergy. 2009;64:1109-16.

28. Di Eusanio M, Wesselink RM, Morshuis WJ, Dossche KM, Schepens MA. Deep hypothermic circulatory arrest and antegrade selective cerebral perfusion during ascending aorta-hemiarch replacement: a retrospective comparative study. J Thorac Cardiovasc Surg. 2003;125:849-54.

29. Hagl C, Ergin MA, Galla JD, Lansman SL, McCullough JN, Spielvogel D, et al. Neurologic outcome after ascending aorta-aortic arch operations: effect of brain protection technique in high-risk patients. J Thorac Cardiovasc Surg. 2001;121:1107-21.

30. Ergin MA, Uysal S, Reich DL, Apaydin A, Lansman SL, McCullough JN, et al Temporary neurological dysfunction after deep hypothermic circulatory arrest: a clinical marker of long-term functional deficit. Ann Thorac Surg. 1999;67: 1887-90.

31. Griepp RB. Cerebral protection during aortic arch surgery. J Thorac Cardiovasc Surg. 2001;121:425-7.

32. Khaladj N, Shrestha M, Meck S, Peterss S, Kamiya H, Kallenbach K, et al. Hypothermic circulatory arrest with selective antegrade cerebral perfusion in ascending aortic and aortic arch surgery: a risk factor analysis for adverse outcome in 501 patients. J Thorac Cardiovasc Surg. 2008;135: 908-14.

33. Kruger T, Weigang E, Hoffmann I, Blettner M, Aebert H. Cerebral protection during surgery for acute aortic dissection type A: results of the German Registry for Acute Aortic Dissection Type A (GERAADA). Circulation. 2011; 124:434-43. 


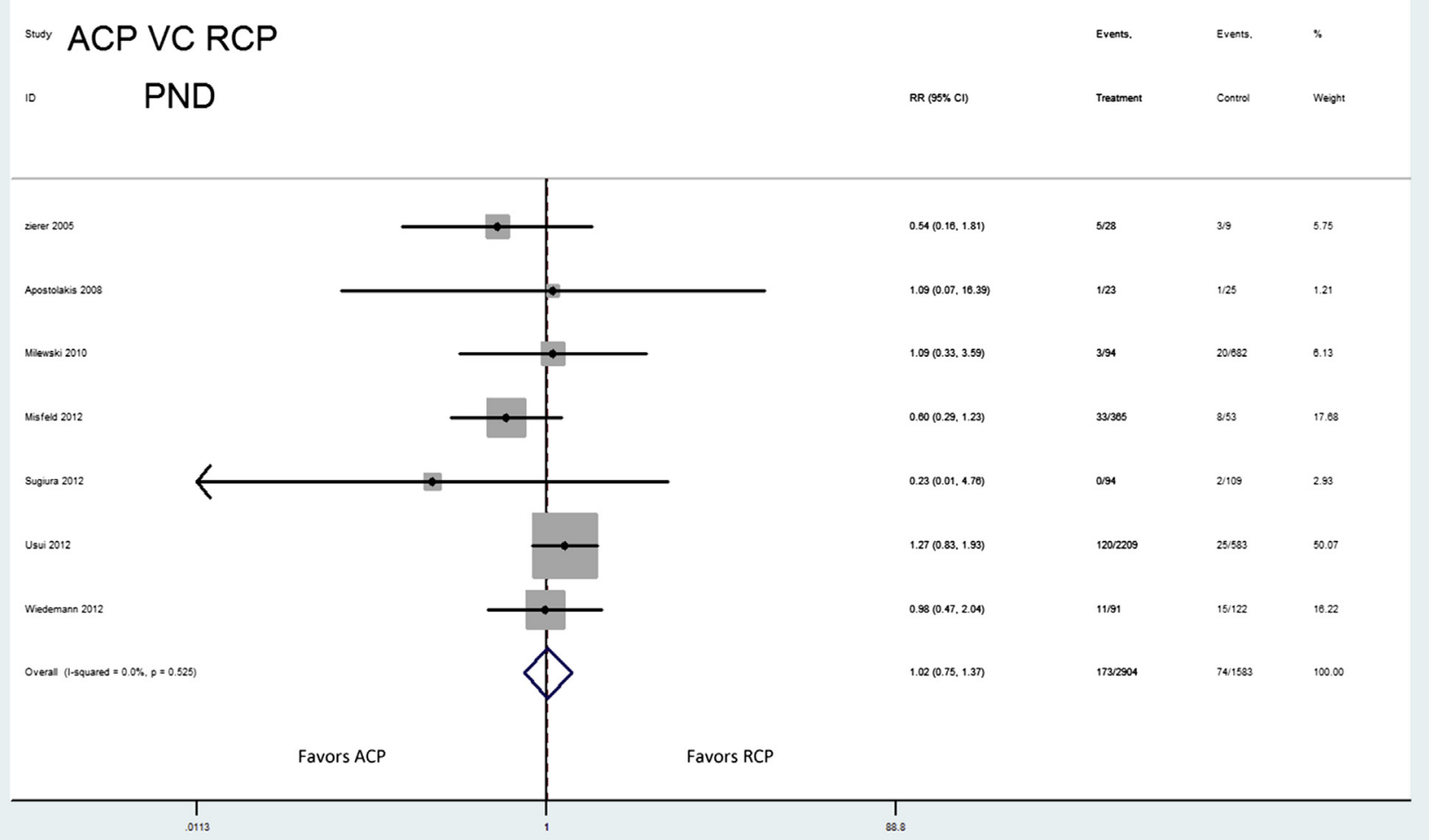

FIGURE 7. Comparison of antegrade cerebral perfusion $(A C P)$ versus retrograde cerebral perfusion $(R C P)$ for morbidity of postoperative permanent neurologic dysfunction $(P N D)$. RR, Relative risk; $C I$, confidence interval. 


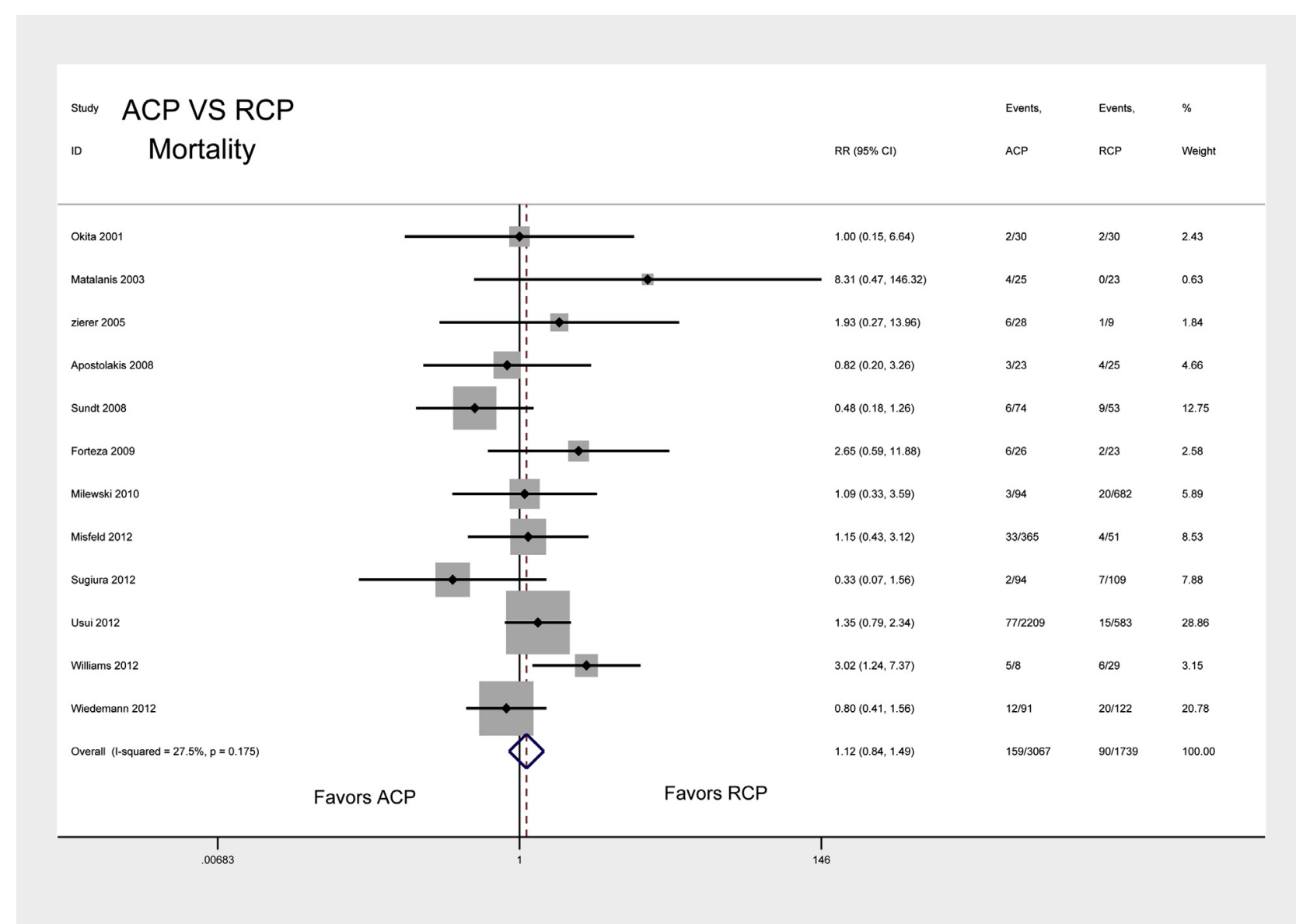

FIGURE 8. Funnel plot of comparison: Morbidity of postoperative permanent neurologic dysfunction. $A C P$, Antegrade cerebral perfusion; $R C P$, retrograde cerebral perfusion; $R R$, relative risk; $C I$, confidence interval. 


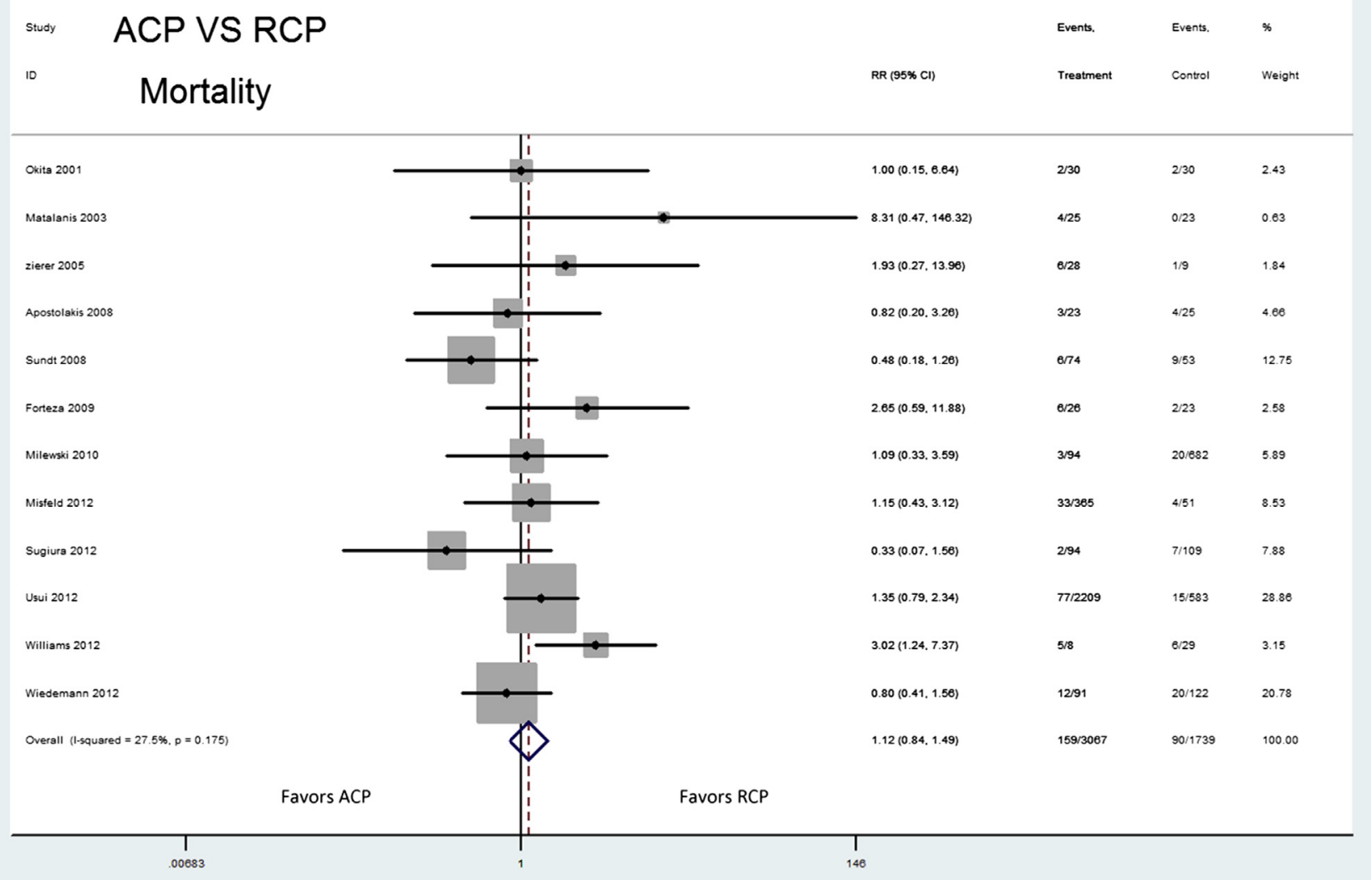

FIGURE 9. Comparison of antegrade cerebral perfusion $(A C P)$ versus retrograde cerebral perfusion $(R C P)$ for postoperative in-hospital mortality. $R R$, Relative risk; $C I$, confidence interval.

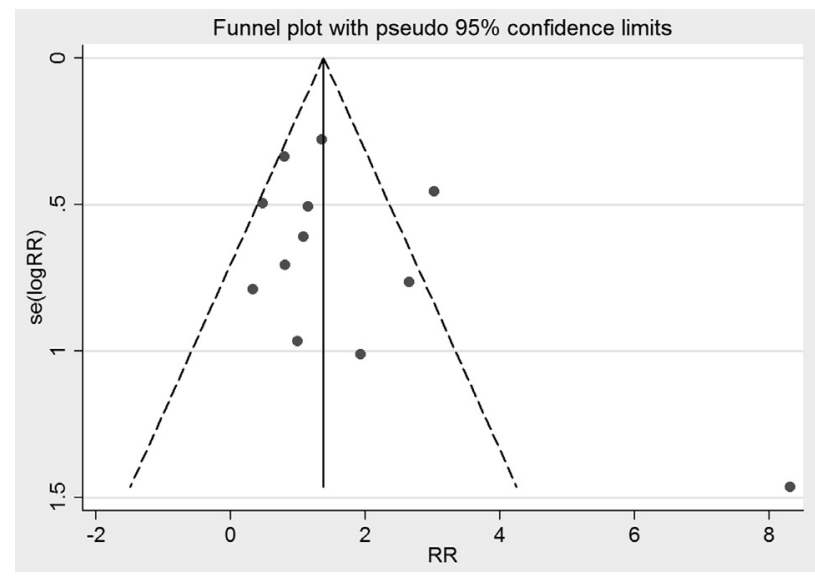

FIGURE 10. Funnel plot of comparison: Postoperative in-hospital mortality. se, Standard error; $R R$, relative risk. 


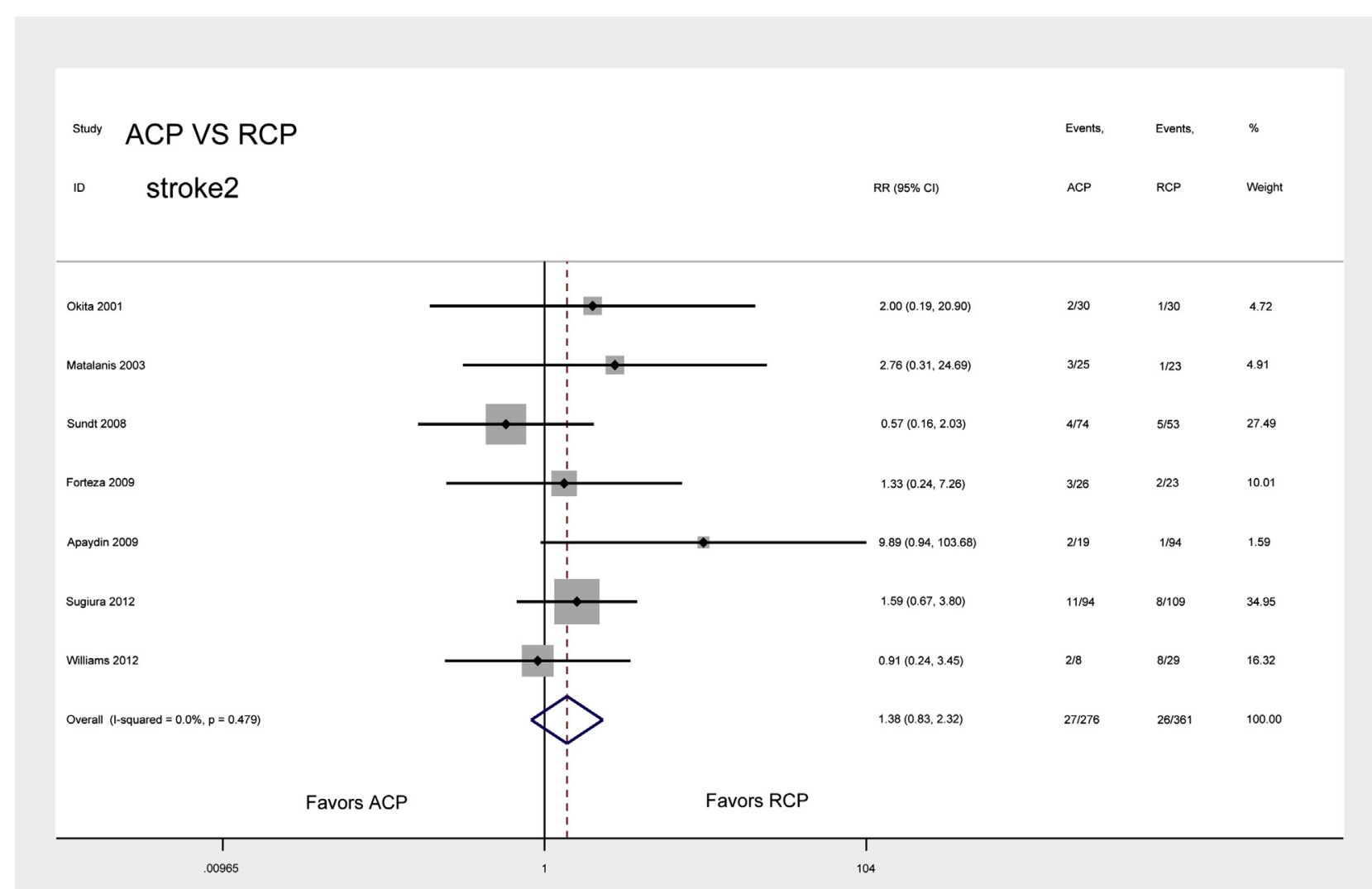

FIGURE 11. Sensitivity analysis of stroke indicating that exclusion of the study by Usui and colleagues ${ }^{20}$ changes the total results most obviously. $A C P$, Antegrade cerebral perfusion; $R C P$, retrograde cerebral perfusion; $R R$, relative risk; $C I$, confidence interval. 


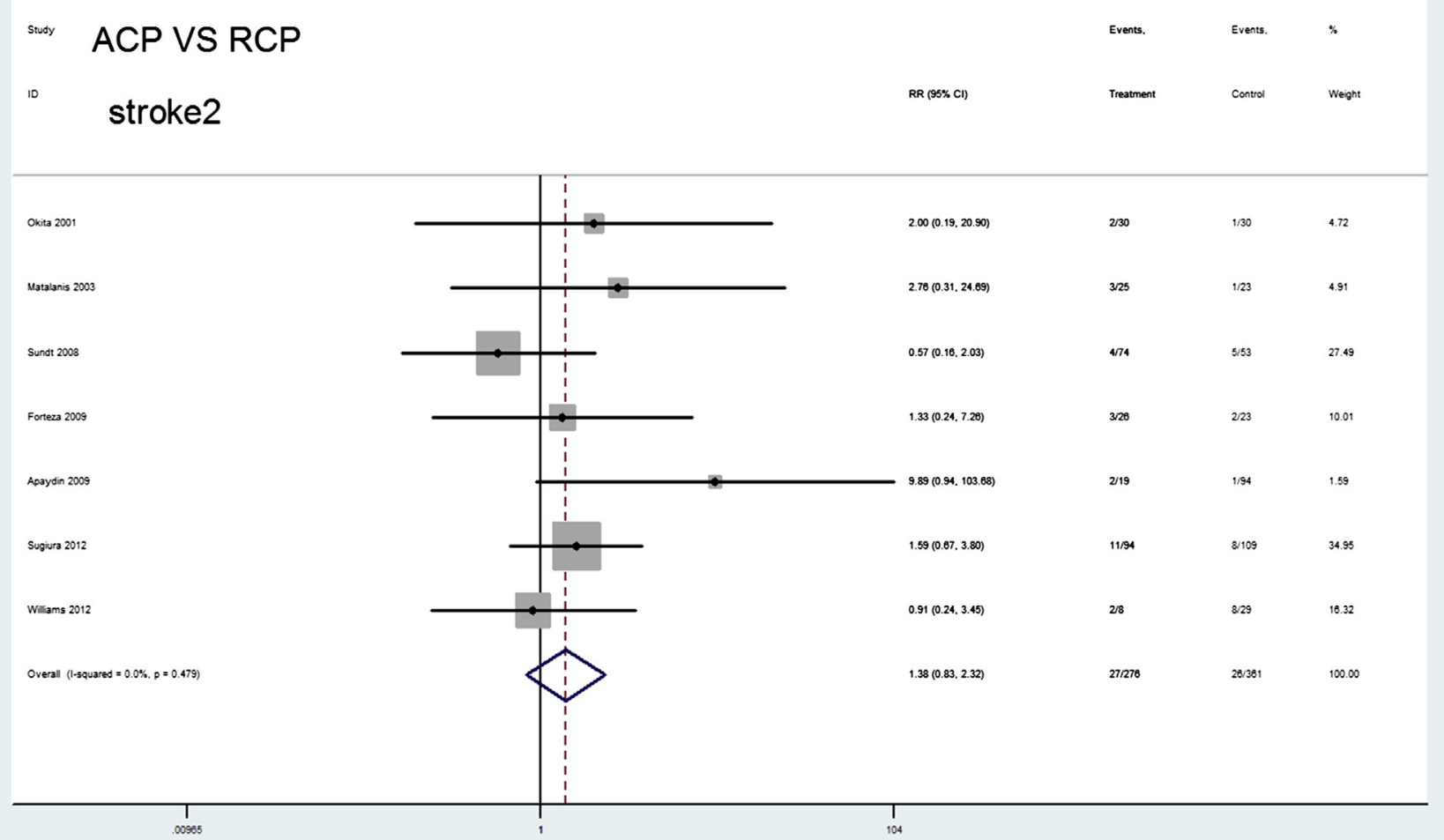

FIGURE 12. Comparison of antegrade cerebral perfusion $(A C P)$ versus retrograde cerebral perfusion $(R C P)$ for morbidity of postoperative stroke after study by Usui and colleagues ${ }^{20}$ was excluded. $R R$, Relative risk; $C I$, confidence interval. 


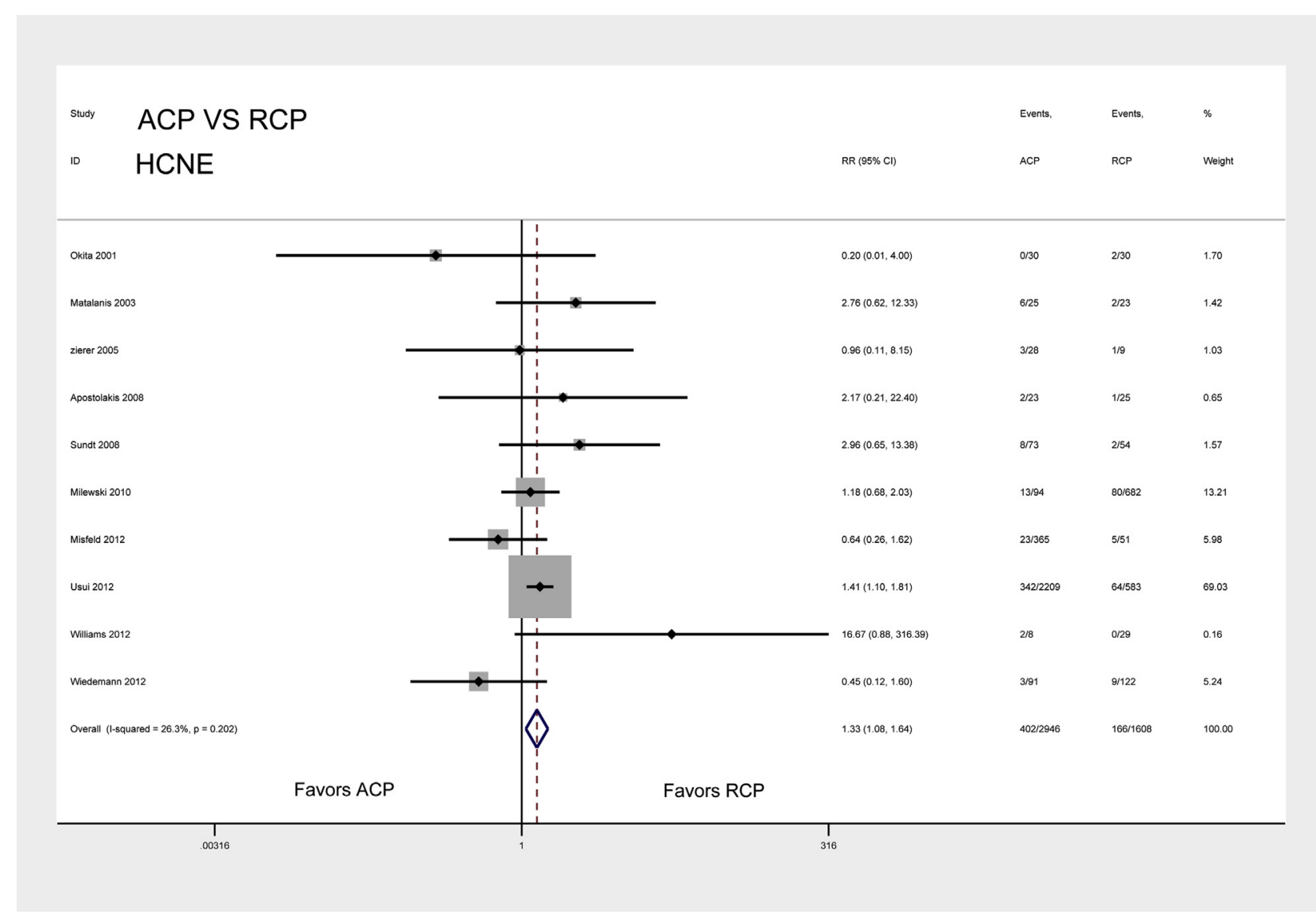

FIGURE 13. Sensitivity analysis of history of central neurologic events indicating that exclusion of study by Usui and colleagues ${ }^{20}$ changes the total results most obviously. $A C P$, Antegrade cerebral perfusion; $R C P$, retrograde cerebral perfusion; $H C N E$, history of central neurologic events; $R R$, relative risk; $C I$, confidence interval. 
swoy $\quad$ ACP VS RCP

10 HCNE2

$\operatorname{RR}(95 \% \mathrm{Cl})$

Events.

$A C$

$0.20(0.01,4.00)$

$\begin{array}{lll}0 / 30 & 2 / 30 \quad 5.50\end{array}$

Okita 2001

Matalanis 2003

zierer 2005

Apostolakis 2008

Sundt 2008

Milewski 2010

Misfeld 2012

Williams 2012

Wedemann 2012

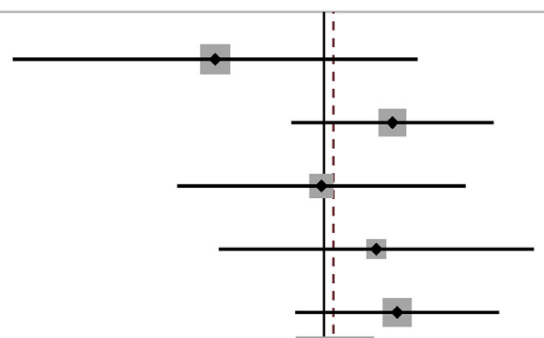

$2.76(0.62,12.33)$

$0.96(0.11,8.15)$

$2.17(0.21,22.40)$

$2.96(0.65,13.38)$

$1.18(0.68,2.03)$

$0.64(0.26,1.62)$

$16.67(0.88,316.39$

$0.45(0.12,1.60)$

$1.15(0.80 .1 .66)$

Favors RCP

OVerall (1-squared $=28.9 \%, p=0.188$ )

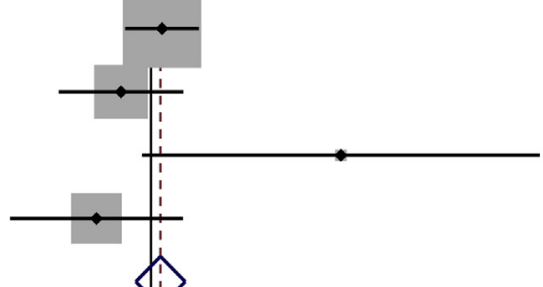

Favors ACP

$\underset{.00316}{1}$

$\prod_{316}^{1}$

FIGURE 14. Comparison of antegrade cerebral perfusion $(A C P)$ versus retrograde cerebral perfusion $(R C P)$ for history of central neurologic events $(H C N E)$ as 1 of the baseline data. $R R$, Relative risk; $C I$, confidence interval. 


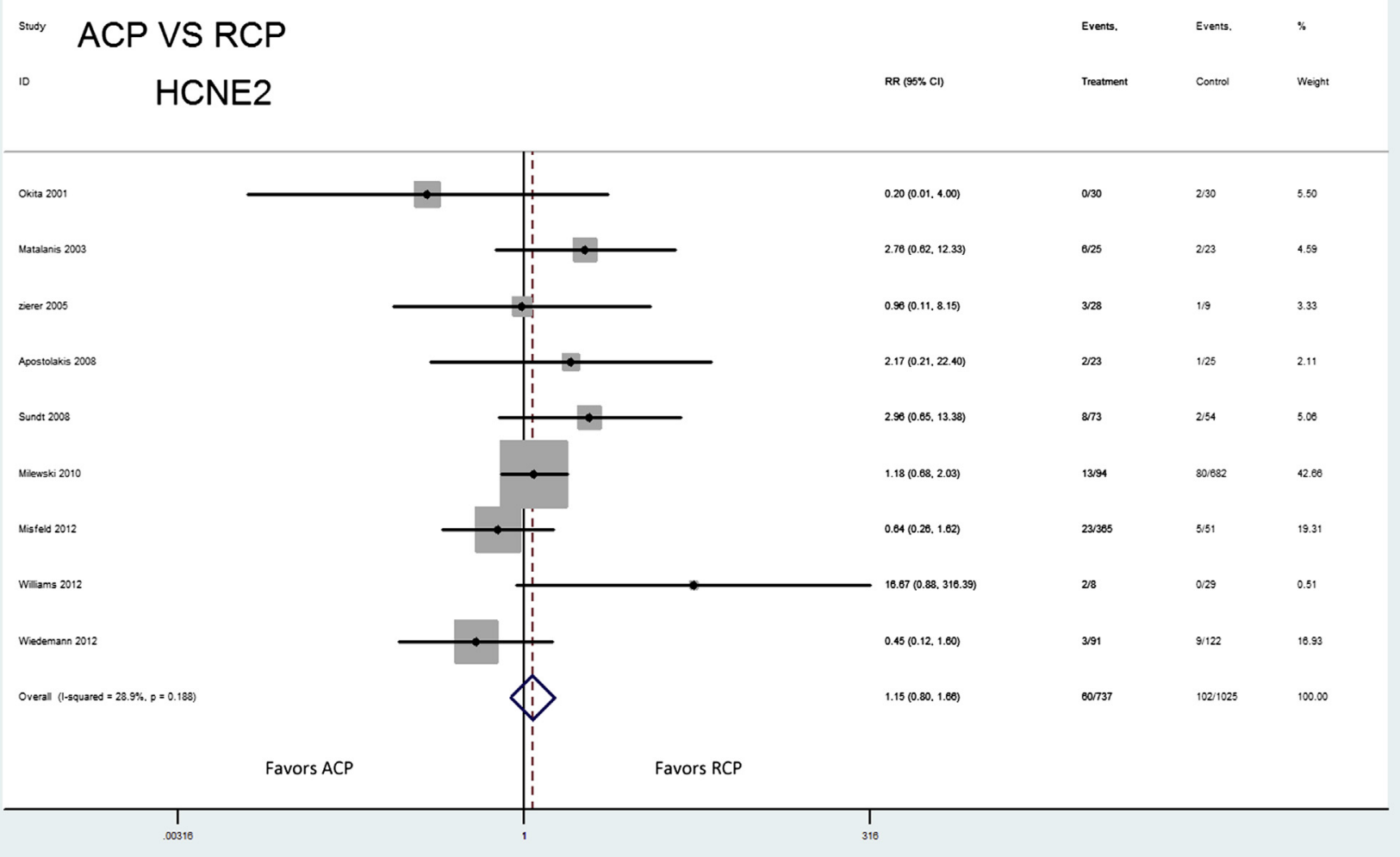

FIGURE 15. Comparison of antegrade cerebral perfusion $(A C P)$ versus retrograde cerebral perfusion $(R C P)$ for history of central neurologic events $(H C N E)$ after the study by Usui and colleagues ${ }^{20}$ was excluded. $R R$, Relative risk; $C I$, confidence interval. 